\title{
An Economic Instrument to Address Beach Wrack
}

\author{
Jan Stenis $^{1}$, Varvara Sachpazidou ${ }^{2} \&$ William Hogland ${ }^{2}$ \\ ${ }^{1}$ LundaHydro AB, Borgholm, Sweden \\ ${ }^{2}$ Department of Biology and Environmental Science, Linnaeus University, Kalmar, Sweden \\ Correspondence: Jan Stenis, LundaHydro AB, Borgholm, Sweden.
}

Received: October 13, 2020

doi:10.11114/aef.v8i1.5100

doi:10.11114/aef.v811.5100

\section{Abstract}

\section{Objectives}

This article introduces a practical, economic instrument based on the Naturally Optimised Revenue Demand in Communities, the NORDIC model, to improve the management of beach wrack. Tourism is an important sector in a country's or region's economy, as it generates employment and business opportunities. Verifiably, sandy shorelines have served as areas for amusement and as attractions upon which tourism advancement has been based. The accumulations of beach wrack result in a significant decrease in the recreational value of a coastal area. The decomposition of beach wrack emits an unpleasant odor, as it releases essential nitrate, phosphate and hydrogen sulfide $\left(\mathrm{H}_{2} \mathrm{~S}\right)$. In this investigation, we provide coastal communities with a powerful tool to address the harmful damage inflicted on their beaches, by marine biomass mounds.

\section{Methods}

We adapted the NORDIC model and used a case study to illustrate how the adapted NORDIC model could alleviate the municipalities' burden, caused by beach wrack.

\section{Results}

The application of a versatile tool, the NORDIC model, by various managers in manage and promote a sustainable use of beach wrack would boost the tourism industry in coastal areas.

\section{Conclusions}

We recommend the application of the NORDIC model to beach wrack management in general, and in particular to the tourism sector, to enhance the economic value of attractive shores. Future research should focus on developing additional algorithms for valuation of specific kinds of beach wrack.

Keywords: beach wrack, NORDIC model, economic instrument, tourism, municipalities

\section{Introduction}

Coastal regions are one of the foremost well-known visitors' destinations around the world. All things considered, vital long-term coastal administration may be a difficult assignment as natural phenomena and unexpected events occur in exposed coastal areas. Some of the issues currently faced by a coastal supervisor entail addressing the expanding request for marine and coastal tourism from the sightseers. Such sightseers ordinarily promote financial activities and increase the human populace at the coast. This demand is also accompanied by the need to support business and recreational activities, as well as infrastructural development, while concurrently balancing the need to preserve the natural coastal landscape.

Furthermore, the coastal landscape is affected by the dynamic effects of the sea and weather conditions. This is due to the complex interface between marine and terrestrial ecosystems. Understanding the scope, characteristics and the dynamic nature of the coastal environment is vital to the management of the resultant effect of such issues in the coastal zones. In coastal marine environments, excessive beach-cast accumulations of plant 'wrack' on beaches form large meadows that are widely distributed along all coastlines of the world.

Beach wrack is defined as the accumulation of organic material washed up on the beach by tides, wind and waves. Following this, beach wrack breaks down and is recycled by natural processes, for example wind-driven changes in 
water lever or along the shoreline, back into the ecological chain in coastal and marine environments (Macreadie et al., 2017).

Beach wrack has a direct impact on the increase of eutrophication and appears in certain seasons of the year. Eutrophication is considered as one of the most serious global threats to coastal areas as it causes gradual changes in the natural, ecological balance. Eutrophication leads to blooming of seasonal macroalgae and a subsequent increase in biomass production. Apart from these ecological effects that eutrophication has on the aquatic ecosystem, eutrophication has also important social and economic implications. Potential regional economic consequences may include past and future losses of important fisheries and marine biodiversity, the disappearance of commercially important species, unfavorable impact on human health that increases public health costs, the presence of infected waters, a decrease in the amenity value of drinking-water that becomes unsuitable for human consumption, loss of recreation venues and/or tourist attraction sites, and the loss of aesthetic value of beaches (McCrackin et al., 2016). Traditionally, beach wrack has been used as organic fertilizer in agriculture or to enrich community-compost. Usually, local councils collect beach wrack material and transfer it to a point close to the beach. At the end of the tourist season, the beach wrack is returned to its original location. Commercially harvested beach wrack can be used as building insulation material or for the composite reinforcement of acoustic insulation panels, or as packaging materials. In other recycling processes, beach wrack is a constituent of materials used for the restoration of emerging and flooded coastal areas. The practical processing of the beach wrack, as an organic waste, can contribute to the fulfilment of the circular economy concept.

The presence of massive amounts of beach wrack or litter in coastal areas portrays an unhealthy environment with poor aesthetic value (Corraini et al., 2018) and is one of the main reasons people may refrain from visiting a coastal area (Ryan, 2014; Schuhmann, 2011; Williams \& Micallef, 2009). This in turn leads to a reduction in income generated from visitors to a coastal area (Krelling et al., 2017). The correlation between the removal of beach wrack for aesthetic and public-health reasons (Schlacher et al., 2016) is interesting. According to Stelling-Wood et al. (2016), a moderately wrack-cleaned beach is analogous level to a beach in the absence of wrack. Thus, removal of wrack is economically sound, and has been approved in many British coastal areas which then experienced economic growth thereafter (Mouat et al., 2010). Never-the-less, such actions distort the local food chains, and eliminate valuable nutrients and different species from the sea (Del Vecchio et al., 2017; Malm et al., 2004). Furthermore, beach wrack supports communities of resident and migratory shorebirds (McCulloch 1996; Christie \& Jessop 2007; Campbell \& Anderson 2007) and contributes to the protection and stabilization of the shoreline, coastal lines and dunes by acting as a physical barrier between the dune system and the sea (PIRSA 2014). Griffin et al. (2018) recommend that relocation of wrack collection from high season tourists visiting seaside resorts, to nearby non-urban beaches, can be used to degrade the wrack. Local councils remove and dispose this material in a variety of ways.

The loss of visitors from a particular seaside resort impacts the economy, the socio-cultural aspects of the persons living in these regions, and the local environment (Portman \& Brennan, 2017). Detailed examination of beach wrack management by Risén et al. (2017) illustrated that suitable coastal environmental programs and strategies may have the potential to realize welfare benefits or reduce welfare losses to coastal communities living in areas with excessive algae biomass. This emphasizes the importance of non-market values of environmental programs in a local or regional state in efficient decision-making.

Despite its exploratory nature, this article attempts to provide new insights into how coastal communities can establish strategies and environmental programs to cope with large amounts of marine biomass. The objective of this study is to introduce an economic instrument for the environmental management of beach wrack. Employing an evidence-based tool, we adapted the Naturally Optimised Revenue Demand in Communities, the NORDIC model (Stenis, 2020abcde; Stenis \& Hogland, 2019) to alleviate problems posed by beach wrack. The NORDIC model will be employed to reduce damages on the economy and the tourism sector by serving as a decision-tool for authorities, politicians and citizens interested in the composition and ecological properties of beach wrack.

\section{Methodological Approach}

\subsection{The NORDIC Model's Social and Economic System}

The NORDIC model is a tool used to monitor, manage and evaluate how firms' or communities' economic, technological and environmental performance changes over time. This method involves adding shadow costs to economic systems. A shadow cost, or a shadow price, is a monetary value assigned to unknown costs (Shadow Price, 2020). Using the NORDIC tool, these shadow costs are inserted into an entity's accounting systems. Changes over time, that occur in the constructed shadow costs, facilitate the reduction in inefficiencies allocated to shadow costs, in declining order of commercial and/or environmental importance. Given the logic of the mathematical theories underlying the NORDIC model and case studies conducted, the NORDIC model produces robust results. 


\subsection{Case Study Area}

The area where the study was conducted was the island of Öland, the second-largest Swedish island of the Baltic Sea coast of Småland. Öland's shores are among the most beautiful Swedish sceneries with outstanding natural and cultural landscapes. The tourism sector in Öland facilitates the development of local utilities for a flourishing society. The potential benefits of sustaining tourism include, significant area-vitality, urban development, sharing economy, boosted communication and efficient cooperation between stakeholders and protectors of the cultural heritage. All these benefits contribute to stakeholder engagement and economic growth on the island.

\subsection{Research Methods}

The NORDIC model served as a base for this study. This concept was further developed into an expression adapted to fit beach wrack. The developed model was then tested in case studies that utilized real-world facts and figures in a setting where the status of the beach highly influenced local businesses. The main hypothesis of this study was that problems due to beach wrack could be alleviated by applying the NORDIC model. Our main goal was to facilitate the daily use of the NORDIC model in beach wrack management. The Böda beach area in Borgholm municipality of Sweden was chosen as the subject of our case studies for two reasons: firstly, beach wrack presents a significant problem to the beaches in Borgholm, and secondly, the island Öland, on which Borgholm is situated, boasts an extensive tourism sector.

Results of this study have the potential to improve the economic, environmental and technological standards in beach wrack management as well as the living conditions of communities utilizing the beach. The study intends to fill the research gap that exists in the literature concerning novel economic instruments to manage beach wrack. The research questions addressed were: 1) How can we use the NORDIC model to improve the economic efficiency of tourism-dependent municipalities, such as Borgholm? 2) How can an economic tool be developed for this purpose? 3) Who would benefit from such an endeavor? 4) Who, other than municipalities, could potentially use this model? It is anticipated that the answers to these questions would guide civil servants and financiers connected to beach wrack issues in beach wrack management and inform interested citizens.

This research could contribute to a better understanding of how beach wrack management could be facilitated by the application of economic instruments. This paper introduces a new method to address an existing problematic situation of beach wrack. This aimed to provide managers with a single, key factor to monitor, manage and evaluate their beach wrack-projects.

The research problem was analyzed from the public's perspective. This approach was aimed at modifying models and theories by using only a few parameters to move the research frontier ahead. Our intention was to present applications of the economic model theory to the welfare sector. The foremost scientific tool for accomplishing this was the case study technique.

An analytical approach was applied to develop theories and models. The hypotheses were analyzed and verified. Potential consequences and plausible causes were identified. Information was gathered through public Internet sources and personal E-mail contacts. Empirical facts were observed to induce theories and deduce predictions to obtain and verify new facts relevant to this scientific study.

An analytical-logic approach was applied to modify the present economic models. A descriptive systems theory was used for the model. A non-personal positivistic approach was chosen. An attempt was made to describe and establish the results, and to predict and guide the discussion. The prediction was tested to induce the discussed theories. Concrete actions were suggested to address the problem. Recommendations were made to different actors, based on the main findings generated from this study.

The quantitative research methodology employed implied that scientists were detached from most parts of the study. The translation from theory to empiric underpinned the operationalization of our ambitions related to algae biomass by employing the defined concepts in certain, exemplified units. The processing of neutral data took place in real-life case studies.

Traditional economic modelling was used to validate the methods we developed. The reliability of our results was enhanced by the use of relevant literature and the case studies.

The graph in Fig. 1 was made using the diagram-function in MS Word. The input variables used were figures constructed in the vicinity of the value for X used in the case studies. The economic instruments (EIs) developed in this study were based on financial incentives, and hence strengthened the dialogue between the current actors.

\subsection{Research Design}

The design selected emphasized a logical-historical disposition. It followed a research process that comprised a description of the background, presentation of the problem and the theory that underpins it, description of the data 
collection and processing methods, the results' analysis and the final conclusions and recommendations. Explanative, explorative processes were used to investigate the causal relationships between variables in the proposed model.

Briefly, the research methods used in this paper were as follows: Firstly, we provided a descriptive introduction to this work that highlighted the importance of the subject. The rationale for conducting this study was then detailed. We then explained the acronym NORDIC and its scientific basis (Stenis, 2020abcde; Stenis \& Hogland, 2019). The literature review that followed displayed the existing relevant, scientific information on beach wrack economy and modelling theory. Following this, a methodology section detailed the mathematical basis for the NORDIC model and logical equations that would be applied to study objects. The analysis section that followed illustrated the general principle of how the NORDIC model could be used to address the beach wrack situation and direct managers on how to act when the Shadow cost $S$ changed. Next, a practical manual was given to show how the NORDIC model could be applied in a stepwise manner. Ultimately, conclusions were listed, the theory-limitation was given, and future research suggested. Finally, the benefits of using the model and recommendations for application of the NORDIC model to 'wrack' were provided.

\subsection{General Foundation of the NORDIC Model Theory}

The NORDIC model gives a shadow cost that mirrors the development of the study subject (which in this case refers to a region's or country's economy, environmental status and attractiveness of the tourism sector).

$$
\mathrm{S}=(\mathrm{X} / \mathrm{Y}) * \Sigma \mathrm{Z} * \mathrm{~W}=((\Sigma \mathrm{V}-\Sigma \mathrm{C}) / \mathrm{Y}) * \Sigma \mathrm{Z} * \mathrm{~W}
$$

where $\mathrm{S}$ is the constructed shadow cost for the subject to be improved; $\mathrm{X}$ is the net worth of the subject to be improved; $\mathrm{V}$ are the Values of the subject $\mathrm{X}$ to improve; $\mathrm{C}$ are the Costs for the subject $\mathrm{X}$ to improve; $\mathrm{Y}$ is the total value of the organization; $\mathrm{Z}$ are the values of the entity's products and services, related to $\mathrm{X} ; \mathrm{W}$ is a sort less weight factor. Sort: tons, liters, Joule, SEK and/or USD etcetera.

\subsection{Theory for Application of the NORDIC Model to Beach Wrack}

Here, we feature tourism as being impacted by beach wrack. The NORDIC model, expressed by Eq. (2), gives a shadow cost that mirrors how successful the beach wrack is utilized by a certain municipality.

$$
\mathrm{S}_{\text {beach wrack }}=((\Sigma \mathrm{V}-\Sigma \mathrm{C}) / \mathrm{E}) * \Sigma \mathrm{T}
$$

where $\mathrm{S}_{\text {beach wrack }}$ is the (positive) Shadow cost for the beach wrack; V are the Values of the utilized beach wrack; $\mathrm{C}$ are the Costs for the not utilized beach wrack; E is the community's Expenses; $T$ are the values of the municipality's Tourism; a Preference factor P for beaches can be applied. Sort: SEK or USD.

\subsection{Application of the NORDIC Model to Municipalities}

$\mathrm{S}$ beach wrack is added into the municipalities' accounts as a constructed, but useful, shadow cost. Table 1 shows the general principle guiding the insertion of $\mathrm{S}_{\text {beach wrack }}$ in the public ledgers.

Table 1. A municipality's profit and loss account

\begin{tabular}{c}
\hline Revenues \\
$S_{\text {beach wrack }}$ \\
\hline Expenses \\
\hline Public Sector Borrowing Requirement (PSBR) \\
\hline
\end{tabular}

\subsection{General Decision Rules when Applying the NORDIC Model}

A reduced PSBR, due to an increasing $S_{\text {beach wrack }}$ over time, points at a more successful beach wrack-policy than in the preceding time point. A raised PSBR due to a lowered $S_{\text {beach wrack }}$ calls for action to improve the municipality's beach wrack-policy. However, the NORDIC model does not detail the methods through which this ought to be implemented; it only provides management with an indication of the beach wrack status. Such information could be used as a basis to identify which specific management-tools to employ.

\subsection{Manual for Practical Application of the NORDIC Model to Beach Wrack}

The following steps should be used when applying the NORDIC model to beach wrack issues.

1. Estimate the values of the parameters by consulting public sources.

2. Calculate the constructed shadow cost $S_{\text {beach wrack }}$ using data programs. 
3. Regularly re-estimate the parameters in Eq. (2) to support decision-making.

4. Regularly re-calculate $S_{\text {beach wrack }}$ to track its' development over time.

5. Take actions if the $\mathrm{S}_{\text {beach wrack }}$ decreases to address challenges posed by the beach wrack situation.

\subsection{Case Study: Application of the NORDIC Model to Borgholm}

This case study relates to Borgholm municipality located on the island of Öland. Grontmij (2010), estimates that approximately 1500 tons of algae flush up on each kilometer of the beach on the east coast of Öland on an annual basis. Böda Sand is about 400 meters wide. Thus, about 600 tons $(1500$ tons $* 400 \mathrm{~m} / 1000 \mathrm{~m})$ of beach wrack accumulates each year at the Böda Sand beach. Organic fertilizer (with a similar effect to that of beach wrack) cost about USD360 / ton (Göran Larsson, Lantmännen, 2020, E-mail communication). Thus, the annual value of the beach wrack from Böda Sand is approximately kUSD216 (600 tons * USD360/ton) $=\Sigma \mathrm{V}$ The annual labor cost for cleaning the Böda beach from its 'wrack' is approximately USD4 000 (60 hours per year * USD65 / hour) plus the fuel and depreciation costs of approximately USD1000, in total USD5 000 (USD4 $000+$ USD1000) $=\Sigma \mathrm{C} \mathrm{E}=$ USD89 million (Borgholm municipality, 2019). $\Sigma \mathrm{T}=$ USD170 million (Öland's municipality union, 2018). An exchange rate of USD1 = SEK10 (January 2020) was then applied. Eq. (2) gives:

$$
\begin{gathered}
\mathrm{S}_{\text {municipal beach wrack }}= \\
((\text { MUSD0.216 }- \text { MUSD0.005) } / \text { MUSD89 }) * \text { MUSD170 = MUSD0.403 }
\end{gathered}
$$

Table 2. Borgholm's profit and loss account

\begin{tabular}{c} 
Revenues \\
$S_{\text {municipal beach wrack }}=\mathrm{kUSD} 400$ \\
Expenses \\
\hline PSBR $-S_{\text {municipal beach wrack }}=\mathrm{PSBR}-\mathrm{kUSD} 400$ \\
\hline
\end{tabular}

Table 2 shows the impact of the constructed shadow cost $\mathrm{S}$ on the economy of Borgholm.

\subsection{Sensitivity Analysis of the NORDIC Model's Application to Beach Wrack}

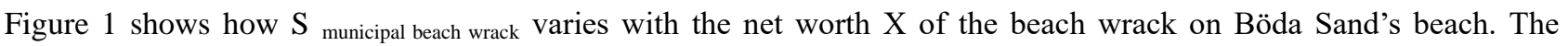
relationship between the Shadow costs and net worth of beach wrack is linear, implying that the NORDIC model is insensitive to various inputs.

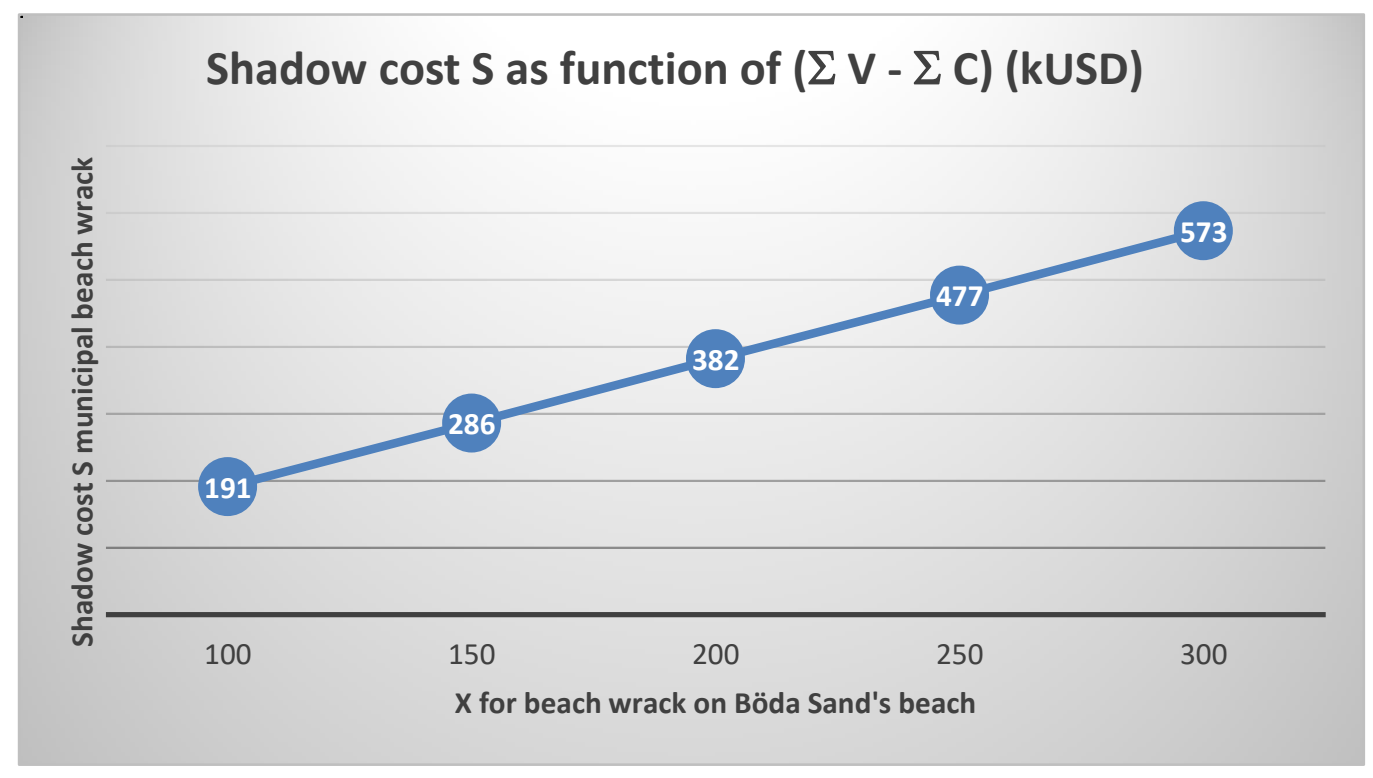

Figure 1. The relationship between $\mathrm{S}_{\text {municipal beach wrack }}$ and the net worth $\mathrm{X}$ for beach wrack at Böda Sand. 


\section{Results and Discussion}

The needs of the past necessitated the current modification of the NORDIC model. The NORDIC model takes into consideration common aspects of beach wrack policy, because the NORDIC model uses currency to express factors relevant to 'wrack' management. To the best of our knowledge, no other approaches that concurrently reduce the negative impact of beach wrack on seaside resorts and improve municipalities' economy by employing a single key factor, exist in the literature.

Beach wrack is preventable by the application of the NORDIC model. This phenomenon has numerous benefits and hence has a substantial commercial and environmental potential.

Thus, our work potentially contributes to a substantial upswing in the tourism sector, which obtains better public finances for the municipalities in question. Furthermore, our effort could increase the possibilities of the public enjoying sceneries of high aesthetic value.

This case study produced a shadow cost of kUSD400 which is equivalent to 4 per thousand of Borgholm's municipality expenses, and hence can be viewed as a reasonable shadow cost. The theory, design and realistic outcomes from this case study illustrate that indeed beach wrack can be reduced and managed by applying EIs, such as the NORDIC model.

\section{Conclusion}

To the best of our knowledge, previous studies have not employed a single key factor to simultaneously monitor, manage and evaluate economic losses imposed by beach wrack over time on citizens who regularly use beaches as tourist resorts and vacation destinations. The present study provides such a tool to beach wrack managers, making this paper important to the tourism sector worldwide as regards the management of global coastline attractions.

Our main hypothesis was that beach wrack could be addressed by applying the NORDIC model. This hypothesis was verified due to the mathematical correctness of the equations produced and the realistic outcomes from case studies used. The main goal of our study was to facilitate the daily use of the NORDIC model. This goal was realized based on the comprehensible and easily applicable expressions that we developed in day to day practice. The study results filled research gaps by availing new economic instruments to manage beach wrack, i.e. Eq. (2).

The research questions we addressed were as follows:

1) How can we use the NORDIC model to improve the economic efficiency of tourism-dependent municipalities, such as Borgholm? By the successful application of the NORDIC model to beach wrack management, in Böda Sand beach.

2) How can an economic tool be developed for this purpose? This tool can be developed through the development of Eq. (2) and its design, that allowed multiple applications.

3) Who would benefit from that commercial and environmental endeavor? The main stakeholders targeted by this tool are beach wrack managers in municipalities concerned about its tourism, such as Borgholm. The main benefit of this endeavor would be the enhanced experience of the tourists on a global scale, who like spending their holidays on long, white and clean beaches.

4) Who, apart from municipalities, are the other potential end-users of this tool? These users include tourist authorities and local businesspersons, who would thrive by using the model.

Our main result was that the NORDIC model improved the beach wrack situation. The main limitation of this theory was its imprecision in pinpointing specific kinds of wrack; nevertheless, this could be addressed by developing additional algorithms.

Therefore, employing EIs has a positive impact on the shore tourism sector. We conclude that the NORDIC model indeed is a tool that could feasibly address problems posed by beach wrack, as the model alleviated problems caused by beach wrack on a local and global scale.

This research conducted on the NORDIC model led us to the conclusion that the NORDIC model could be an answer to the economic problems faced by tourist destinations in many countries, due to the presence of beach wrack. Businesses and local economies could benefit from EIs, such as the NORDIC model, that highlights the economic benefits of biomass recycling.

\section{Benefits and Recommendation}

This study explored the feasibility of a valuation-approach in estimating the economic and environmental benefits associated with a reduction in beach wrack. From this study, we gained insights on what future research related to valuation of the beach wrack could entail.

\subsection{Potential Benefits of Study Results}

The main benefits of this study were: 
1. Financial benefits following a reduction in beach wrack, in the touristic coastal areas.

2. The attraction of concerned residents to longer, whiter and cleaner beaches.

3. A reduction in costs of algae biomass by removal of beach wrack on the coastal beaches.

4. Diminished financial losses and increased profits, due to less 'wrack' on the beaches.

5. An estimate of the financial benefits associated with reduction of beach wrack.

6. The use of beach wrack as a fertilizer, to support sustainable, organic farming.

7. The accomplishment of a sustainable tourism strategy, through the NORDIC model.

8. The definition of a methodology to reach the shore-tourism sector.

9. Better dissemination of information about the 'wrack' situation.

10. An enhancement of education, to support sustainable development of coastal regions.

\subsection{Recommendation}

We recommend that municipal and other managers and program-officers etcetera, that are concerned about the accumulations of algae biomass in the coastal areas, apply the NORDIC model to beach wrack management in general, and in particular to tourism sector issues, related to the economic value of attractive shores.

\section{Compliance with Ethical Standards}

6.1 Funding

Funding to conduct this study was provided by the Conversion of a Nuisance to a Resource and Asset, the CONTRA project. This project was supported by the European Regional Development Fund, ERDF.

\subsection{Disclosure of Potential Conflicts of Interest}

The authors declare no conflicts of interest.

\subsection{Availability of Data and Material}

All data generated or analyzed during this study are included in this published article. No repository exists for the raw data.

6.4 Research Involving Human Participants and/or Animals

No human participants or animals were involved in this study.

\subsection{Authors' contribution}

Jan Stenis and Varvara Sachpazidou drafted and edited the paper. Jan Stenis, the corresponding author for this paper, designed the study and customized his NORDIC model to fit beach wrack purposes. Varvara Sachpazidou conducted the literature review and reviewed the paper. William Hogland, the principal investigator for the CONTRA project on Öland, was involved in concept development and reviewed the manuscript.

\section{Acknowledgements}

The authors are grateful to Ms. Kristin Bertilius, staff at the Borgholm municipality, Mr. Göran Larsson, the Commercial Product Manager for fertilizers at Lantmännen, and Mr. Calle Olofsson, the Manager at Böda Sand beach resort, all from Sweden, for providing data that was fed into these case studies.

\section{References}

Böda Sand. (2020). About Böda Sand, in Swedish. Retrieved from https://jobb.bodasand.se/departments/aktivitet

Borgholm municipality. (2019). Annual report 2018, in Swedish. Retrieved from https://www.borgholm.se/wp-content/uploads/2019/04/Arsredovisning-2018-KF-190415_78.pdf

Campbell, J., \& Anderson, R. (2007). Shorebirds on the beaches of the Limestone Coast in the South East of South Australia. Part A: Shorebird disturbance on the beaches of the Limestone Coast, 2006-2007. A report prepared by Friends of Shorebirds SE for the Shorebird Conservation Project/WWF Australia.

Christie, M., \& Jessop, R. (2007). Shorebird sites of the Limestone Coast South East of South Australia. Part B. A report prepared by Friends of Shorebirds SE for the Shorebird Conservation Project/WWF Australia.

Corraini, N. R., de Lima, A. D., Bonetti, J., \& Rangel-Buitrago, N. (2018). Troubles in the paradise: Litter and its scenic impact on the North Santa Catarina island beaches, Brazil. Marine Pollution Bulletin, 131, 572-579. https://doi.org/10.1016/j.marpolbul.2018.04.061

Del Vecchio, S., Jucker, T., Carboni, M., \& Acosta, A. T. R. (2017). Linking plant communities on land and at sea: The effects of Posidonia Oceanica wrack on the structure of dune vegetation. Estuarine Coastal and Shelf Science, 184, 30-36. https://doi.org/10.1016/j.ecss.2016.10.041

Griffin, C., Day, N., Rosenquist, H., Wellenreuther, M., Bunnefeld, N., \& Gilburn, A. S. (2018). Tidal range and 
recovery from the impacts of mechanical beach grooming. Ocean \& Coastal Management, 154, 66-71. https://doi.org/10.1016/j.ocecoaman.2018.01.004

Grontmij. (2010). Biogas - new substrates from the sea, report.

Krelling, A. P., Williams, A. T., \& Turra, A. (2017). Differences in perception and reaction of tourist groups to beach marine debris that can influence a loss of tourism revenue in coastal areas. Marine Policy, 85, 87-99. https://doi.org/10.1016/j.marpol.2017.08.021

Macreadie, P. I., Trevathan-Tackett, S. M., Baldock, J. A., \& Kelleway, J. J. (2017). Converting beach-cast seagrass wrack into biochar: A climate-friendly solution to a coastal problem. Science of the Total Environment, 574, 90-94. https://doi.org/10.1016/j.scitotenv.2016.09.021

Malm, T., Raberg, S., Fell, S., \& Carlsson, P. (2004). Effects of beach cast cleaning on beach quality, microbial food web, and littoral macrofaunal biodiversity. Estuarine Coastal and Shelf Science, 60(2), 339-347. https://doi.org/10.1016/j.ecss.2004.01.008

McCrackin, M. L., Jones, H. P., Jones, P. C., \& Moreno-Mateos, D. (2016). Recovery of lakes and coastal marine ecosystems from eutrophication: A global meta-analysis. Limnology and Oceanography, 62, 507-518. https://doi.org/10.1002/lno.10441

McCulloch, E. (1996). Save our seaweed. The Bird Observer, 764, 2-4.

Mouat, J., Lozano, R. L., \& Bateson, H. (2010). Economic impacts of marine litter. KIMO International, pp. 105. Retrieved from https://www.kimointernational.org/

Öland's municipality union. (2018). Öland's municipality union for overall planning: Budget including activity plans 2019 with plan for 2020 and 2021, in Swedish. Retrieved from https://www.olandskommunalforbund.se/wp-content/uploads/2019/07/OlkomBudget2019.pdf

Portman, M. E., \& Brennan, R. E. (2017). Marine litter from beach-based sources: Case study of an Eastern Mediterranean coastal town. Waste Management, 69, 535-544. https://doi.org/10.1016/j.wasman.2017.07.040

Primary Industries and Regions of South Australia (PIRSA). (2014). Ecological Assessment of the South Australian Beach-Cast Seagrass and Marine Algae Fishery. Assessment report prepared for the Department of the Environment for the purposes of part 13 and 13(a) of the Environment and Protection and Biodiversity Conservation Act 1999.

Risén, E., Nordström, J., Malmström, M. E., \& Gröndahl, F. (2017). Non-market values of algae beach-cast management - Study site Trelleborg, Sweden. Ocean \& Coastal Management, 140, 59-67. https://doi.org/10.1016/j.ocecoaman.2017.02.009

Ryan, P. G. (2014). Litter survey detects the South Atlantic 'garbage patch'. Marine Pollution Bulletin, 79(1-2), 220-224. https://doi.org/10.1016/j.marpolbul.2013.12.010

Schlacher, T. A., Lucrezi, S., Connolly, R. M., Peterson, C. H., Gilby, B. L., Maslo, B., ... Schoeman, D. S. (2016). Human threats to sandy beaches: A meta-analysis of ghost crabs illustrates global anthropogenic impacts. Estuarine, Coastal and Shelf Science, 169, 56-73. https://doi.org/10.1016/j.ecss.2015.11.025

Schuhmann, P. W. (2011). Tourist perceptions of beach cleanliness in Barbados: Implications for return visitation. Études Caribéennes 19. https://doi.org/10.4000/etudescaribeennes.5251

Shadow Price. (November 19, 2020). In Wikipedia, the free encyclopedia. Retrieved November 20, 2020, from https://en.wikipedia.org/wiki/Shadow_price

Stelling-Wood, T. P., Clark, G. F., \& Poore, A. G. B. (2016). Responses of ghost crabs to habitat modification of urban sandy beaches. Marine Environmental Research, 116, 32-40. https://doi.org/10.1016/j.marenvres.2016.02.009

Stenis, J. (2020a). An economic instrument to improve migration. Applied Economics and Finance, 7(1), 15-20. https://doi.org/10.11114/aef.v7i1.4630

Stenis, J. (2020b). Application of the Naturally Optimised Revenue Demand in Communities NORDIC model to improve the workforce in Sweden. Applied Economics and Finance, 7(2), 18-23. https://doi.org/10.11114/aef.v7i2.4711

Stenis, J. (2020c). Application of the Naturally Optimised Revenue Demand in Communities NORDIC model to improve the education in Sweden. Theoretical Economics Letters, 10, 523-534. https://doi.org/10.4236/tel.2020.103033

Stenis, J. (2020d). An economic instrument to improve the climate in Sweden. Theoretical Economics Letters, 10, 
758-769. https://doi.org/10.4236/tel.2020.104047

Stenis, J. (2020e). An economic instrument to reduce the crime rate in Sweden. Archives of Business Research, 8(10), 121-130. https://doi.org/10.14738/abr.810.9282

Stenis, J., \& Hogland, W. (2019). An economic instrument to improve communities. Theoretical Economics Letters, 9 , 1804-1816. https://doi.org/10.4236/tel.2019.96115

Williams, A. T., \& Micallef, A. (2009). Beach Management: Principles and Practice. London: Earthscan.

\section{Copyrights}

Copyright for this article is retained by the authors, with first publication rights granted to the journal.

This is an open-access article distributed under the terms and conditions of the Creative Commons Attribution license which permits unrestricted use, distribution, and reproduction in any medium, provided the original work is properly cited. 